\title{
William M. Lougheed and the Development of Vascular Neurosurgery at the Toronto General Hospital
}

\author{
J. Max Findlay
}

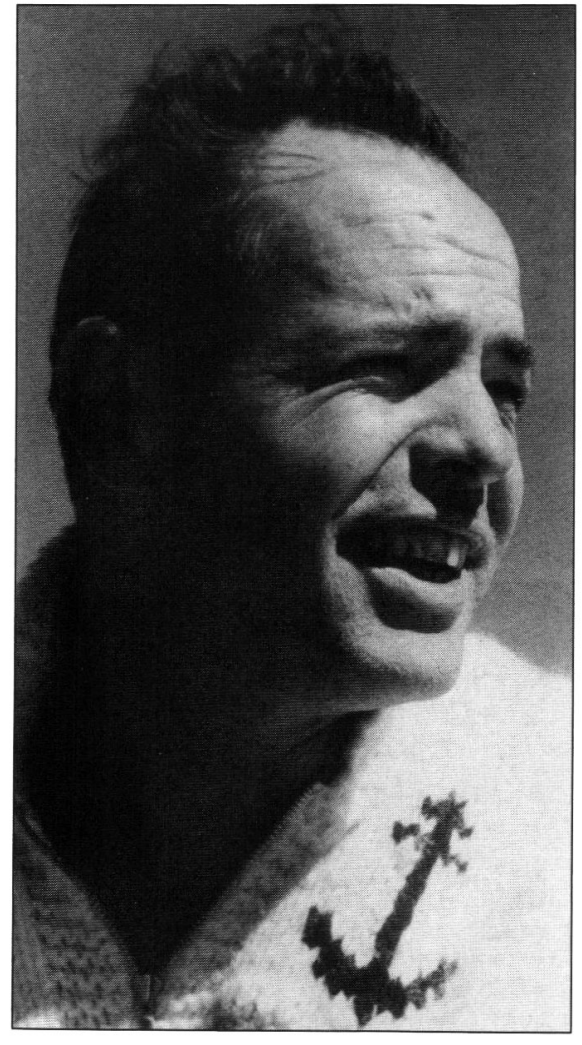

Figure I-Dr: William $M$. Lougheed, circa 1960.

Dr. Bill Lougheed was able to navigate residents through even the most complex neurosurgical procedures with complete and often heroic patience, always ensuring for the patient his usual expert technical result but still leaving intact the resident's sense of pride and achievement, the feeling that he, the resident, "had done it". A gifted technical surgeon, a thoughtful and inventive neurosurgeon, Dr. Lougheed was above all else one of Canada's great teachers of operative neurosurgery. Canada's pioneer microneurosurgeon, Dr. Lougheed brought the Toronto General Hospital to the very forefront of the emerging field of vascular neurosurgery.

William MacMurray Lougheed was born July 9, 1923 at the Toronto General Hospital. His father, Gladstone Wilfred ("Stoney") Lougheed was a respected Toronto internist and pathologist, and his only, older sibling, Joseph Charles, was also to follow a medical career, in vascular surgery. Bill Lougheed attended Upper Canada College in Toronto and then the University of Toronto, graduating from medical school in 1947 and obtaining a Bachelor of Science in 1949 (Physiology). His performance on the neurosurgical service as junior intern at Toronto General Hospital won him a position as a neurosurgical candidate in the Toronto Gallie Course in surgery, commencing in 1949.

\section{Surgical training with Gordon Murray, Kenneth McKenzie and Harry Botterell}

During his early surgical training Lougheed was particularly influenced by one of the most imaginative and skillful surgeons in Canada's history, Dr. D.W. Gordon Murray of the Toronto General Hospital. At the end of his year of general surgery Gordon Murray and colleague Wilfred G. ("Bill") Bigelow asked young Lougheed to switch to cardiovascular surgery. E. Harry Botterell had already decided he wanted Lougheed on the neurosurgical staff, but left the choice to Bill Lougheed with his blessing whatever course he followed. The intellectual challenge of neurological examination and diagnosis convinced Lougheed to continue in neurosurgery, but he would teach the principles of surgical technique and vascular surgery instilled into him by Gordon Murray his entire career.

Dr. Lougheed began his neurosurgical training under Kenneth G. McKenzie and E. Harry Botterell. Dr. McKenzie had become Canada's first neurosurgeon in 1923 after returning to the Toronto General Hospital from a year's training with Harvey Cushing, and he eventually founded the first neurosurgical training program in Canada. ${ }^{1.2}$ Dr. Lougheed acquired McKenzie's flair for the technical aspects of neurosurgery, and he emulated

From the Division of Neurosurgery, University of Alberta, Edmonton Received October 19, 1992. Accepted in final form January 29, 1993

Reprint requests to: J. Max Findlay, 2D1.02 W.C. Mackenzie Health Sciences Centre, 8440 - 112 Street, Edmonton, Alberta, Canada T6G 2B7 
McKenzie's unflappable behavior in the face of any intraoperative calamity. McKenzie retired as director of neurosurgery in 1952, and the capable Harry Botterell became "Chief" at the midpoint of Lougheed's neurosurgical training. ${ }^{3}$

\section{Hypothermia in neurosurgery}

Despite very discouraging surgical results at the time, Harry Botterell firmly believed that neurosurgeons would eventually solve the problem of cerebral aneurysms and vascular lesions of the brain, and he encouraged Lougheed to pursue an interest in blood vessels. Dr. Lougheed, inspired by the work of cardiac surgeon Bill Bigelow of the Toronto General Hospital, who had introduced the concept and technique of hypothermia for open heart surgery, decided to establish a model of hypothermia and reversible cerebral circulatory arrest for neurosurgery. His idea was that vascular lesions of the brain could be treated more adequately if the blood supply to the affected area was briefly occluded or at least diminished under the protection of a cold brain. In 1952 Lougheed went to Dr. William H. Sweet's laboratory in Boston and studied the biochemical and physiological responses to cerebral anoxia after either regional or systemic hypothermia in dogs. In these experiments, the first of their kind, it was found that systemic hypothermia to approximately $25^{\circ} \mathrm{C}$ could safely reduce the cerebral metabolic rate to about $25 \%$ of normal with corresponding protection from anoxia for 15 to 22 minutes. ${ }^{4}$ Before leaving the Massachusetts General Hospital Lougheed assisted in the first two clinical applications of hypothermia in neurosurgery world-wide, ${ }^{5}$ which established that hypothermia and temporary cerebral anoxia were feasible in humans.

Dr. Lougheed returned to Toronto in 1954 for his final year of neurosurgical training under Harry Botterell, who embraced the concept of hypothermia and, along with Lougheed, Dr. Stuart L. Vandewater (anaesthesia) and Dr. John W. Scott (neurophysiology) commenced its use almost immediately. The detailed report of this method in Botterell's first 22 patients with ruptured intracranial aneurysms, published in $1956,{ }^{6}$ began a new era in aneurysm surgery. This paper, which was the world's first description of hypothermia and temporary cerebral circulatory arrest for aneurysm surgery, is also remembered for grading patients with varying severity of subarachnoid hemorrhage, the first such grading system of its kind. Temporary cerebral circulatory arrest was indeed a useful adjunct in those early days, since 17 of the 22 primarily acute aneurysms ruptured during dissection or clipping, yet there were only 3 deaths and 16 good or excellent outcomes.

\section{Cerebrovascular research and the beginning of microneuro- surgery in Canada}

Dr. Lougheed obtained his Royal College certification in neurosurgery in 1955, and following a McLaughlin travelling fellowship in Europe he took a staff position at the Toronto General Hospital in 1956. Given a small laboratory at the Banting Institute, Lougheed's first animal research project was development of a ventricular assist device which he hoped would be able to take over from a frigid, noncontractile heart, and thus overcome this great threat of hypothermic neurosurgery (those being the days before heart-lung machines and cardiopulmonary bypass). Drs. Lougheed and Mary Tom devised a model of subarachnoid hemorrhage in dogs where a needle inserted through a burr hole in the hard palate was used to inject blood directly into the region of the circle of Willis, thus providing a good approximation of the pathophysiological events following rupture of an aneurysm in that location. ${ }^{7}$

The advantages of an operating microscope first became apparent to Lougheed in the laboratory, and in the early 1960's he began a series of experiments in microvascular reconstruction using suture, contact cement and Teflon graft, a microstapling technique, and other methods. ${ }^{8-10}$ These investigations were similar to work being done at the same time in Dr. Pete Donaghy's microsurgical laboratory in Burlington, Vermont, and Lougheed and Donaghy frequently collaborated in their mutual and, at that time, unique interest in microsurgery. The laboratory microscope was occasionally used for clinical cases at Toronto General Hospital, but Dr. Lougheed insisted that a manoeuverable, double-headed surgical diploscope that provided both surgeon and assistant simultaneous binocular vision, was necessary for neurosurgical procedures. The eventual development of such a surgical microscope enabled Lougheed to become one of the world's first, and Canada's first, microneurosurgeon.

\section{Aneurysm surgery, the long-vein bypass, and carotid endarterectomy}

In the 1960's hypothermia and temporary, global cerebral circulatory arrest in aneurysm surgery was gradually supplanted by a combination of delay in the time of aneurysm repair (when the risk of intraoperative rupture is less) and by the safe and easy induction of hypotension during aneurysm dissection and clipping. " Microsurgical techniques and instrumentation also helped obviate the time-consuming and demanding process of hypothermia and surgical exposure of the major vessels in the neck.

Lougheed, along with Toronto jeweller Harry S. Kerr, designed an innovative aneurysm clip in 1964.12 This new clip had an adjustable spring that varied the closing force of the clip blades, thus enabling the surgeon to lighten the closing pressure of the clip for use, when necessary, in temporary, atraumatic vascular occlusion. Instead of global extracranial vascular occlusion under the protection of hypothermia or deep systemic hypotension, Lougheed was among the first in the world to recommend local intracranial control through temporary parent vessel occlusion with softer aneurysm clips.

In 1969 Lougheed and neuroanesthetist Dr. Brian Marshall reported a series of 40 patients with ruptured aneurysms repaired with the operating diploscope, ${ }^{13}$ Canada's first series of microsurgically operated aneurysms and one of the largest such series in the world at that time. In the same year Lougheed introduced the important concept of overall management mortality and morbidity (surgical plus nonsurgical cases) versus selected surgical results when describing outcome of patients with aneurysmal subarachnoid hemorrhage. ${ }^{14}$ His microsurgical approaches to the various anterior circulation aneurysms, along with results in 657 aneurysm cases seen at the Toronto General Hospital, were described in $1973 . .^{15}$

In 1965 Dr. Lougheed reported one of the world's first successful cases of microsurgical intracranial embolectomies. ${ }^{16}$ Another technical achievement was the world's first long-vein 
bypass procedure where a saphenous vein was anastamosed proximally to the common carotid artery and distally to the internal carotid artery above the anterior clinoid process, bypassing an occluded cervical internal carotid artery (1971). ${ }^{17}$

In 1953, Lougheed, as a research fellow, and Dr. H. Hamlin, attending neurosurgeon at the Massachusetts General Hospital, performed a segmental internal carotid arterectomy and end-toend anastamosis in a middle aged woman who had suffered a stroke. ${ }^{18}$ This same procedure, which was one of the world's first surgical corrections of carotid stenosis, was performed the following year by Eastcott, a vascular surgeon at St. Mary's Hospital in London, but Eastcott's case became the first ever reported when it was published in Lancet in 1954. ${ }^{19}$ Cooley et al.'s description of a true carotid endarterectomy appeared in $1956,{ }^{20}$ about the same time that Lougheed began performing endarterectomies in Canada at the Toronto General Hospital. In 1966 Lougheed, Robert Elgie and neurological colleague, Henry Barnett, reported on their first 109 patients undergoing endarterectomy for carotid artery occlusion or stenosis, the first series of this size in Canada. ${ }^{21}$ By the end of his surgical career Dr. Lougheed had performed over 1000 carotid endarterectomies, and he taught generations of neurosurgeons his technique.

\section{Resident teaching}

In the early 1970's Dr. Lougheed began refusing all speaking invitations and decided to stop presenting papers at scientific meetings. The near monthly trips away from his family and practice, and the constant pressure to prepare new material, had taken their toll. Over the ensuing years Lougheed's international recognition faded, and while others have regretted this retirement from the limelight at the height of a brilliant career, Dr. Lougheed, who had different ambitions, has not.

One of Dr. Lougheed's most important contributions was training neurosurgeons at the University of Toronto. He excelled as a teacher of operative neurosurgery, emphasizing preoperative preparation and intraoperative organization. He taught, by example, how to properly treat and use assistant and scrub nurse to "get the most out of them", regardless of their neurosurgical expertise. Above all, he required that you "keep your cool under fire". He had the gift of being able to teach on first principals, and he was always willing to share his worst mistakes in order that you might avoid them. His own sensitivity revealed itself in a certain sullen and terse behavior at times, but never acrimony; he felt deeply for his patients and it was always plain when he had been injured by a poor outcome.

Characteristic of an original thinker, Dr. Lougheed always treated new ideas and innovations as opportunities instead of affronts and dangers. He was unable to complete his last project, the invention of a technique of rapid, nonsuture vascular anastamosis that would enable neurosurgeons to quickly, safely and easily make vascular connections deep within the brain. ${ }^{22}$ In December, 1989, at age 66, Lougheed removed his gloves after excising a large convexity meningioma from a young woman and announced to a startled theater that he had just completed his last operation. Not even his secretary for nearly 30 years, Mrs. Joan Kane, knew in advance. The Toronto General Hospital, the birthplace of neurosurgery in Canada, and where Lougheed was born, trained, and where he had spent his entire surgical career, closed all neurosurgery within its doors the following spring when the division transferred to the Toronto Western, ${ }^{23}$ with which it had merged to form the Toronto Hospital. Although perhaps not having achieved the persistent world fame that others might have wished for him, Dr. Lougheed retired from neurosurgery having won, for him, a greater reward: the affection, loyalty and respect of several generations of men and women he had helped make neurosurgeons.

As a boy Bill Lougheed began spending his summers with his grandfather at Go Home Bay on Georgian Bay, Ontario. His grandfather, an architect, built boats during these summer months, and passed on to his grandson a similar love of wood, carpentry and boat building. This preoccupation with boats and water, and the splendor of Georgian Bay, has served as Dr. Lougheed's lifelong escape and refuge from the rigors of ncurosurgery. Dr. Lougheed and his wife Grace have retired to Barrie, Ontario, closer to Georgian Bay, where all of his five children, Stoney, Bill, George, Jocelyn and Bubba still spend summer vacations.

\section{REFERENCES}

I. Botterell EH. Kenneth George McKenzie, M.D., F.R.C.S., 18921963. Surg Neurol 1982; 17: 81-89.

2. Alexander E. Kenneth George McKenzie, Canada's first neurosurgeon. J Neurosurg 1974; $41: 1-9$.

3. Tasker RR. E. Harry Botterell. Surg Neurol 1984; 21: 215-217.

4. Lougheed WM, Khan DS. Circumvention of anoxia during arrest of cerebral circulation for intracranial surgery. J Neurosurg 1955; 12: $226-232$

5. Lougheed WM, Sweet WH, White JC, Brewster WB. The use of hypothermia in surgical treatment of cerebral vascular lesions. A preliminary report. J Neurosurg 1955; 12: 240-255.

6. Botterell EH, Lougheed WM, Scott JW. Vandewater SL. Hypothermia and interruption of carotid and vertebral circulation in the surgical management of intracranial aneurysms. J Neurosurg 1956; 13: 1-42.

7. Lougheed WM, Tom M. Method of introducing blood into the subarachnoid space in the region of the circle of Willis in dogs. Can J Surg, April 1961; 4: 329-337.

8. Khodadad G, Lougheed WM. Repair of small arteries with contact cement and Teflon graft. J Neurosurg 1964; 21: 552-560.

9. Khodadad G, Lougheed WM. Stapling technique in segmental vein autografts and end-to-end anastomosis of small vessels in dogs. Utilization of the operating microscope. J Neurosurg 1966: 24: 855-864.

10. Khodadad G, Lougheed WM. Repair and replacement of small arteries, microsuture technique. J Neurosurg 1966; 24: 61-69.

11. Lougheed WM, Marshall B. The place of hypothermia in the treatment of intracranial aneurysms. Progr Neurol Surg 1969; 3: 115148.

12. Lougheed WM, Khodadad G. A new clip for surgery of intracranial and small blood vessels. J Neurosurg 1965; 22: 397-398.

13. Lougheed WM, Marshall B. The diploscope in intracranial aneurysm surgery: results in 40 patients. Can J Surg 1969; 12: 75-82.

14. Lougheed WM. Selection, timing and technique of aneurysm surgery of the anterior circle of Willis. Clin Neurosurg 1969; 16: 95-113.

15. Lougheed WM, Marshall BM. Management of aneurysms of the anterior circulation by intracranial procedures. $I n$ : Youmans JR, ed. Neurological Surgery. Philadelphia: WB Sanders Publisher. 1973; 2: 731-767.

16. Lougheed WM, Gunton RW, Barnett HJM. Enbolectomy of internal carotid, middle and anterior cerebral arteries. Report of case. J Neurosurg 1965; 22: 607-609.

17. Lougheed WM, Marshall BM, Hunter KM, Michel ER, SandwithSmyth $\mathrm{H}$. Common carotid to intracranial internal carotid bypass venous graft. Technical note. J Neurosurg 1971; 34: 114-118.

18. Hamlin H, Sweet WH, Lougheed WM. Surgical reconstruction of occluded cervical carotid artery. J Neurosurg 1958; 15: 427-437. 
19. Eastcott HHG, Pickering GW, Rob CG. Reconstruction of internal carotid artery in a patient with intermittent attacks of right hemiplegia. Lancet 1954; 267: 994-996.

20. Cooley DA, Al-Naaman YD, Carton DA. Surgical treatment of arteriosclerotic occlusion of common carotid artery. J Neurosurg 1956; 13: 500-506.

21. Lougheed WM, Elgie RG, Barnett HJM. The results of surgical management of extracranial internal carotid artery occlusion and stenosis. Can Med Assoc J 1966; 95: 1279-1293.
22. Gentili F, Lougheed WM, Yoshijima S, Hondo H, MacKay MB. A technique for rapid non-suture vascular anastomosis. Can J Neurol Sci 1987; 14: 92-95.

23. Tator $\mathrm{CH}$. Special article: new division of Neurosurgery at Toronto Hospital. Surg Neurol 1991; 36: 378-379. 